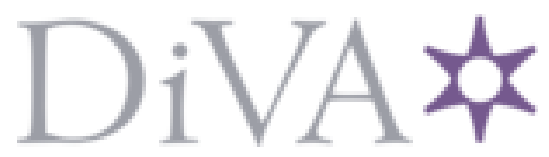

http://www.diva-portal.org

This is the published version of a chapter published in Working and learning in times of uncertainty: challenges to adult, professional and vocational education.

Citation for the original published chapter:

Lindberg, O., Rantatalo, O., Haake, U. (2015)

Police leadership practice in times of uncertainty and organisational turmoil.

In: Sandra Bohlinger, Ulrika Haake, Christian Helms Jørgensen, Hanna Toiviainen, Andreas Wallo (ed.), Working and learning in times of uncertainty: challenges to adult, professional and vocational education (pp. 103-116). Rotterdam: Sense Publishers

Research on the education and learning of adults

N.B. When citing this work, cite the original published chapter.

Permanent link to this version:

http://urn.kb.se/resolve?urn=urn:nbn:se:umu:diva-107675 


\section{POLICE LEADERSHIP PRACTICE IN TIMES OF UNCERTAINTY AND ORGANISATIONAL TURMOIL}

\section{INTRODUCTION}

Resonating on the themes of globalisation, change and uncertainty, the following chapter offers a critical discussion regarding the role of leadership in occupational and organisational ambitions of renewal. An often espoused image of leaders in times of change is that of a guide showing the way for a work-group or organisation on a journey towards the desired future state of being (cf. Gill, 2002). Ironically, leadership of (and in) change in this way often tends to be described as something static and durable in an otherwise transforming environment. From this perspective, leaders are often conceptualised as change agents betrothed in the development of visions of the future that are operationalised into strategies aimed to bring visions to reality (Hooper \& Potter, 2000). As indicated by current research on leadership based on interpretative frameworks (cf. Crevani, Lindgren, \& Packendorff, 2010), images such as these are unfortunate, as they tend to tie leadership to individual 'heroic' leaders with certain formal or informal mandates and thereby obscure several distinguishing characteristics of leadership in times of change and uncertainty.

The present chapter aims to outline a practice theory of leadership based on Schatzki (2001b, 2005). The chapter builds on a study of police leaders and police policy documents (Haake, Rantatalo, \& Lindberg, forthcoming), and in the following, we develop and explain the theoretical underpinning of the practice theory analysis of leadership. We argue that practice theory has merits in the study of leadership, as it allows an adoption of what can be termed a post-heroic view of leadership in which leading is less a question of who leads than what leads in a given situation. Our study takes this as a starting point as we analyse expectations on police leaders. In detail, we use interview data and an analysis of policy documents to analyse leadership in terms of expectations. This entails an attempt to highlight some important facets of the 'nitty-gritty details' of leadership routine and practice (see also Bryman, 2004; Chia \& Holt, 2006; Chia, 2004). In other words, our study follows research that focuses on the 'mundane' (Alvesson \& Sveningsson, 2003) work and expectations of leaders in everyday practice.

With examples drawn from a current case study of Swedish police leadership, the chapter demonstrates the possibility of focusing on leadership in terms of performances (Butler, 1993) taking place within different nexuses of doings and 


\section{O. LINDBERG ET AL.}

sayings (practice). With this aim, the chapter's contribution can be located in the formulation of a framework for research that holds the potential to forward discussions and contribute to knowledge development on the issue of leadership practice without resorting to traditional pitfalls of a heroic view on leadership.

\section{THE MERITS OF A PRACTICE THEORY FRAMEWORK FOR LEADERSHIP RESEARCH}

In recent years, practice theory has been presented as a viable solution to a number of resilient and problematic dualisms of social theory, such as mind-matter and actor-structure (Sandberg \& Tsoukas, 2011; Schatzki, 2001a). In Schatzki's theory, a practice is defined as an organised, open-ended, spatial-temporal manifold of actions (e.g., cooking, farming, policing, and, of course, leading). Schatzki (2005) argues that practice theories are 'site ontologies', taking as their starting point neither individual nor structure but rather action. We should, according to Schatzki, not view an organisation as an array of individuals or as super-individual structures without room for agency.

Instead, the key to understanding 'the practice turn' in contemporary theory is to realise that it is actions rather than people that are organised. Actions are, in Schatzki's theory, primarily organised by understandings, rules and teleoaffectivity. 'Understandings' concern humans' past experiences with how to do things, such as understanding how to bake a cake or use a word processor. 'Rules' concern both explicit rules and laws, 'rules of thumb' and implicit rules of how things should be done. However, Schatzki (e.g., 2001b) devotes most of his explanation of understanding human action to teleoaffectivity. Teleo signifies that actions are goal-oriented; actions are undertaken to accomplish something (even though we often fail to accomplish what we intended) and are thus guided by hopes, beliefs and expectations. Affective, on the other hand, signifies that actions also originate from emotions, moods and, most importantly, what matters to humans. The degree of affection also determines importance to humans and how humans have invested in the carrying out of an action. Hence, Schatzki argues that people do what makes sense to them to do; it is not always what we would recognise as a rational act, but rather, it is dependent on specific goals for the action as well as present affection. This is what Schatzki calls practical intelligibility.

In the present chapter, we conceptualise leadership as a 'site'. This site is an analytical focus on specific performances concerning leading in an organisation. Lindberg $(2012 ; 2013)$ as well as Lindberg and Rantatalo (2015) developed an analysis of interview statements based on the concept of teleoaffective structure in Schatzki's practice theory. Teleoaffective structure is described by Schatzki (2001) as:

... a range of acceptable or correct ends, acceptable or correct tasks to carry out for these ends, acceptable or correct beliefs (etc.) given which specific tasks are carried out for the sake of these ends, and even acceptable or correct emotion out of which to do so. [...] So practices establish social order, first, 
because they help mold the practical intelligibility that governs their practitioners' actions and thereby help determine which arrangements people bring about. (Schatzki, 2001b, pp. 53-54)

However, future actions also shape and reshape this structure. In this way, teleoaffective structure is, as a construct, reminiscent of performativity and citationality in, for instance, the works of Judith Butler (e.g., 1993). To operationalise the concept of teleoaffective structure, our empirical study focuses on the analysis of interviews and documents on espoused leadership performances. A leadership performance is defined as any action thought to be part of leadership, i.e., actions that are signified as belonging to the performance of leadership in the organisation. Bringing teleoaffectivity into the analysis, we also analyse the espoused normative dimension of these performances. Leadership performances are, in other words, described as good (acceptable, correct, desirable) or bad (unwanted, incorrect, undesirable) or as any point on a scale between these two.

The teleoaffective structure of leadership is hence investigated through the normative value that is given to certain leadership performances. We use the term expectations to map the teleoaffective structure governing leadership performance, constructed both around statements that positively (do like this) as well as negatively (do not do like this) point out leadership performance. Expectations on leadership performances are expressed in various forms: formally (as in policy), informally (as during a conversation with a co-worker), directly (as in orders and directives) or indirectly (as in consequences for measures taken in a given situation). Expectations can also be self-driven and self-perceived. In the 'fluidity' of leadership practice (Weick, 1993), demands, wishes and self-evaluations are all a part of teleoaffective structure in which leaders (and others that perform leadership) act and are acted upon.

An important point in focussing leadership performances is that they are not limited to the behaviour of leaders. Leadership research has, particularly within police leadership research, to a great extent been involved with the effectiveness of certain leadership traits and behaviours. As a site ontology, practice theory gives room for other performances and other arrangements (such as material arrangements or other people) performing leadership.

\section{LEADERSHIP IN UNCERTAIN TIMES AND CHANGE}

As an empirical context suitable for the study of leadership in change, it can be concluded that policing institutions in many Western countries currently are undergoing substantial restructuring in the light of changing security discourses and new forms of governance coupled with an era of globalisation. In Sweden, the police currently face developments towards increased public demands on service delivery; changing societal demographics; new security discourses; transnational crime patterns; and increased demands of the police to serve in a 'multifunctional' fashion (Lauritz \& Hansson, 2013). Change pressures such as these have led to attempts of renewed definitions of purposes and methods of policing. Prominent 


\section{O. LINDBERG ET AL.}

examples on the level of reform are, for instance, the incorporation of new public management (NPM) as an administrative restructuring oriented towards service alignment. Also, on an organisational level, a need for change is evident and has been manifested in organisational countermeasures, such as moves from experiential models of policing towards knowledge- and problem-based policing, which builds on evaluation, the utilisation of research, the fostering of learning climates and overall ambitions to become a 'learning organisation' (cf. Andersson Arntén, 2013; SOU, 2012, p. 13). In policy discourse surrounding these transformations, a dominant theme of discussion has targeted the importance of leadership to achieve the successful implementation of changes. For instance, a recently conducted state investigation of the Swedish police organisation (SOU, 2012, p. 13), emphasised how the effective management of police 'for the future' is 'dependent on the development of modern leadership' (e.g. p. 32, emphasis added). However, what this 'modern leadership' is supposed to entail is not elaborated on in the report.

Given that leadership currently is promoted as a solution to many of the Swedish police's current challenges, we aim to exemplify how a practice theoretical analysis of leadership may highlight some of these issues.

The case study seeks to answer how police leaders' accounts of leader practice relate to expectations from higher ranks (above), subordinates (below) and police policies concerning leadership. The case consists of interviews with 28 lower or middle managers in the police (11 women and $17 \mathrm{men}$ ), referred to as police leaders in the present chapter. These leaders were selected from two counties in Northern Sweden and from different ranks of the police organisation, from field officers to the heads of units. They all have responsibilities for staff that perform police work such as patrolling, crime-prevention, investigations or crime-fighting. The police leaders are supposed to assume three roles; as being accountable for operations, as employer representatives, and as leadership practitioners (Rikspolisstyrelsen, 2011b).

With the objective of examining how police leaders' experiences of leadership relate to expectations from higher ranks, from subordinates and from policy, we conducted a content analysis and categorisation of interview statements from 28 police leaders (in quotations named as woman 1-11, man 12-28). This method was combined with analysis of Swedish police leadership expectations as expressed in policy documents.

In order to conceptualise leadership as processual and rooted in performance, the study investigated the relationship between different accounts of leadership performances by constructing different domains of expectations. The domains are empirical categories (originating in the data sources) aimed at making comparisons and cross-references of different expectations. As such, they are constructed simply as the source of the leaders' perceived expectations. The domains were constructed as expectations from policy, expectations from above (i.e., higher ranking topmanagement) and expectations from below (i.e., the subordinated employees). After describing these domains of expectations, the results focus upon how police 
leaders describe their own leadership performances in their day-to-day practices of leadership.

\section{Expectations in Official Police Policy}

Three documents are paramount in defining Swedish police leadership: the police's organisational core values (Rikspolisstyrelsen, 2008), the police's employee policy (Rikspolisstyrelsen, 2011a), and the police's internal leader criteria (Rikspolisstyrelsen, 2011b). These documents are linked to each other with several cross references and can be said to constitute three pillars in defining Swedish police leadership on a policy level. Through content analysis of these documents, we identified 41 different expectations. These are exemplified in the following (for the full presentation, see Figure 1).

Within the core values, three central concepts are put forth as guiding principles for all of the police undertakings. The core values state that the police should work towards increased engagement (from employees internally and externally with local communities); that the police should work in a manner of efficiency (with an orientation towards results); and that the police should strive to be available (both externally and internally).

Building on the core values, the employee policy operationalises a number of desirable leader traits and expectations of leaders regarding what roles to take on in relation to subordinates, stakeholders, and the professional mandate the police must uphold. These roles are described in detail through a number of prescribed performances. Furthermore, the employee policy also discusses leadership on three hierarchical levels: direct leaders (i.e., first-line managers within the police), indirect leaders (i.e., middle management level) and, finally, strategic leaders (who, as the name implies, function on a top-tier strategic level). These levels of leadership are developed within the police's official leader criteria, which further details leadership performances.

Altogether, the policy texts give direction regarding desirable performances connected to the leaders. For instance, the leaders are expected to demonstrate proactivity, pathos, development orientation and facilitation skills in relation to their subordinate workgroups.

\section{Expectations from Top Management and Subordinates}

Starting with what can be referred to as 'top-down' desirable leadership performances, the interviewed leaders describe what kinds of demands and expectations they experience from above. Statements in this section concern performance management as the ability to make the unit perform well and maintain budget. Police leaders' experiences with pressures from above mainly concern expectations on leaders to act as employer representatives and to work towards measurable goals, which includes expectations of effectiveness, economy and performance. Personnel issues (HR management) are largely absent in the expectations on leaders from above. 


\section{O. LINDBERG ET AL.}

The respondents' descriptions of demands and expectations from subordinates (bottom-up) are more varied. 'Soft' issues, such as being a facilitator and working with personnel issues, are mixed with more performance-oriented, result-focused and 'hard' issues. The facilitating areas of demands and expectations concern creating a good work environment and pleasant work conditions for employees. Another considerable area of expectations from below on their leadership performances concerns being a good employee representative by representing the unit from the bottom towards the top of the system, which includes acting as a representative for their employees, shielding the employees from adverse organisational changes and voicing their concerns towards top management.

They also experience expectations of authority from employees, which includes being an employer representative and explaining directions from above. The expectations are also about proactive performances, such as developing the work conditions and creating cohesive activities for the unit.

\section{DOMAINS OF EXPECTATIONS}

Expectations expressed in policy combined with police leaders' perceived demands from below and above are illustrated in Figure 1. Each circle represents a domain of expectations. The letter A signifies expectations from above, and B represents expectations from below. Numbers within parentheses denote how frequently different expectations were mentioned in the interviews.

As the analysis shows, expectations from below show the greatest discrepancy from official policy with a number of expectations of leaders that cannot be found in policy, such as questions about salaries, benefits and vacations. Instead, expectations from above are more formalistic, emphasising result orientation and efficiency. The co-occurrence of expected leadership performances between different domains of expectations are found regarding the leader's role as an authority and employer representative. An interesting finding is also that the majority of expectations formulated in the policy arena do not seem to be reflected in leaders' perceived expectations of their leadership, neither from above nor from below.

\section{Leader Practice as the Management of Expectations}

When the interviewed police leaders describe their own leadership, the most common descriptions are more congruent with demands and expectations from below than from above. The expressions of their own leader practice show that they predominantly, and much more than what is expected and demanded from both higher ranks and from employees, act in a facilitating manner by being stafforiented, being caring, being supportive, being inclusive, being responsive, listening, motivating joy for work and encouraging staff to take responsibility. As a couple of respondents highlighted: 


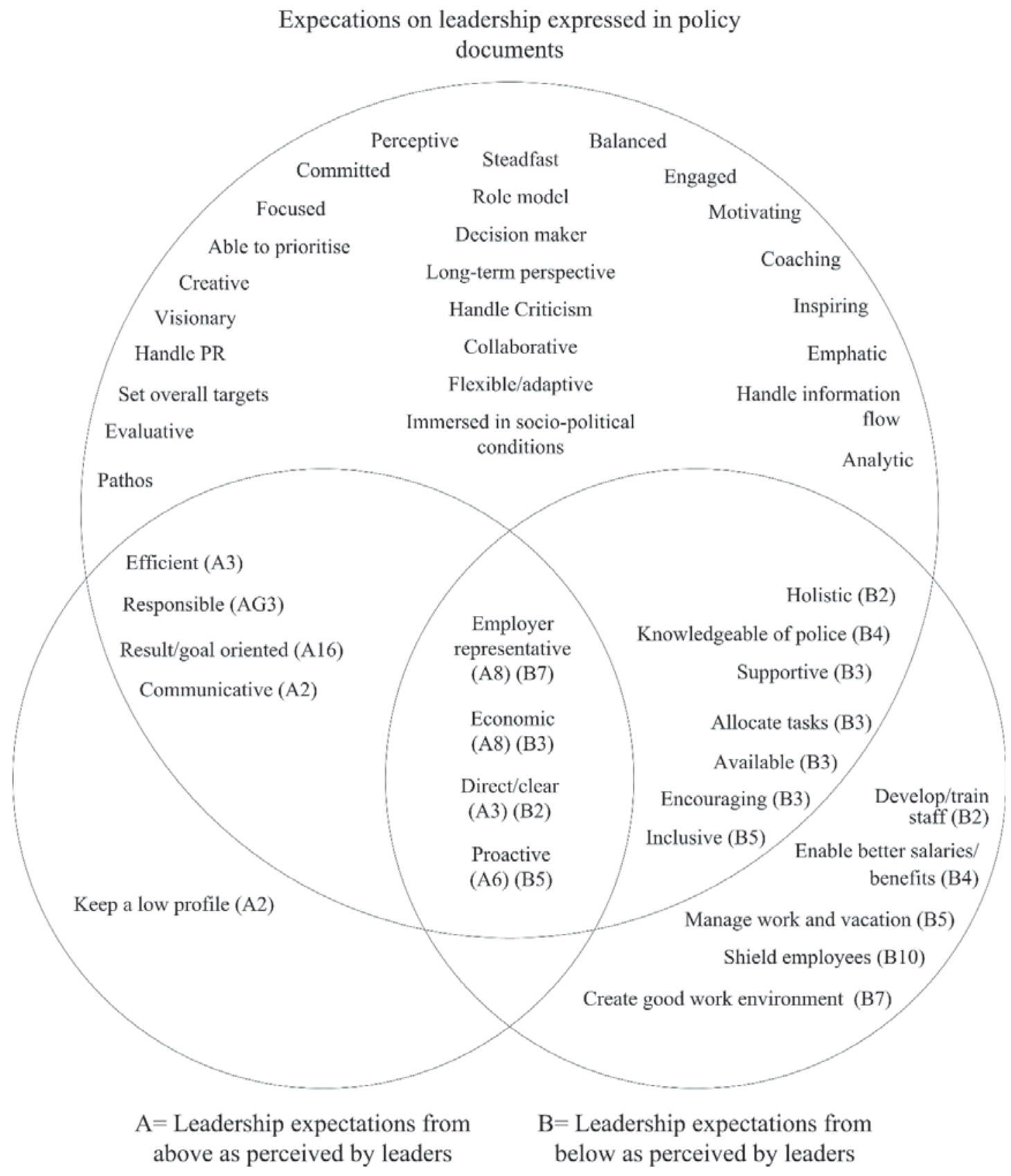

Figure 1. Domains of expectations on leadership performances

I treat people with respect. I'm good at listening and interpreting my subordinates and the general climate at work. My motivation is that they should enjoy their work, and that they should be as content as possible. (Woman 9) 


\section{O. LINDBERG ET AL.}

[My leadership style] is in any case non-authoritarian. What I strive for is that when we, me and my staff, begin a session we plan the day together ... we discuss it together. I listen to what they think we need to do, as well as the demands that are put on us. It is important to do this together. (Man 22)

The descriptions of the respondents' own leadership also show that they value engagement and a motivating approach to leadership, where self-expectations such as being gentle, positive and humorous are important.

Concerning actions of authority (such as being clear and decisive, brave, daring, not afraid of conflicts, exact, accurate, demanding, honest, trustworthy and loyal), the leaders' descriptions of their own practice and expectations from both topdown and bottom-up are very similar.

I believe that they [employees] think I'm kind, but at the same time rather clear and decisive (...) If I think something is not working well (...) I tell them immediately: this wasn't that good. They shouldn't need to second guess what I think and what I value. (Woman 11)

In the same manner, another respondent also emphasised clarity and decisiveness as important facets of self-expectations:

I'm rather direct and clear in regarding what I stand for and think. I (...) try to be as fair as possible. And I'm rather clear about how I want things to be. I'm also rather good at giving feedback and I'm not afraid to say what I find to be demanding things in the system. (Man 24)

Having authority is thereby something that in this study shows to both be expected and acted upon in the leader practice within the police.

Concerning being able as a leader to navigate in the organisation, the respondents emphasised how these abilities were dependent on communicative performances. Expectations regarding experience, skill and strategic performance are mostly of interest in policy texts and are not perceived as important leadership performances from leaders themselves or from above or below. Interesting to note is also that the interviewed leaders refer much less to performances such as being well-organised, goal-focused and result-oriented as a part of their daily leader practice than what is visible in their expressions of top-down and bottom-up expectations. In particular, they describe performance management in terms of expectations from above:

Performance management and good economical results are the big thing right now and have been for a while. Everything seems to be about money and that is often in conflict with being an operative manager and in need of handling acute operations. I can't think of economical things at the same time as I need to handle a mountain rescue where I need a helicopter. (...) Economical demands is the toughest thing to handle when it at the same time requires that we should perform better and deliver more, while at the same time, we get lesser time for the staff. (Woman 2) 
Performances concerning defending and representing the unit's staff against top management is a lesser part of the leaders' descriptions than expected by their subordinates. Instead, they describe some aspects that are neither referred to in policy nor in expectations from above or below that concern authenticity in leadership. Authenticity is described as being able to show weaknesses and allow for being personal.

Yes, I'm stubborn, that I can tell you and then I have problems with dropping questions when I feel I have right even though others say I'm wrong. That is a weakness that I have trouble letting things go. (Man 12)

\section{THE ROLE OF CHANGE AGENTS FROM A PRACTICE THEORY PERSPECTIVE}

Focusing on the teleoaffective structure of leadership practice is asking what matters to these leaders and what makes sense for them to do. By looking at different domains of expectations perceived from above, below and from official policy, we get an overview of different sets of expectations, how they interact or, by contrast, how expectations are not congruent at all. In the second step, we analysed how leaders' account of their own practice related to these domains of expectations.

As opposed to much research on leadership, the practice theory approach does not focus on individual styles, traits and behaviours of leaders. In these other approaches, leadership styles, traits and behaviours tend to be viewed as universal - transferable - and, as such, either effective or ineffective. The practice theory perspective, on the other hand, recognises the contextuality of performance in organisations. Understanding why a certain way of doing things is working or not working to achieve a given goal must be understood by the analysis of context, organisational culture, views of followers and the perceived purpose of the organisation as well as the leaders themselves. In short, an analysis of teleoaffective structure recognises both the contextual as well as the processual nature of leadership.

The other main advantage of a practice theory analysis of leadership concerns the clear focus on performance rather than person or function. Leadership performances can be (and most probably are) carried out by people other than leaders. It is, as stated in the introduction, less a question of who leads than what leads in a given situation. Although we have not had the opportunity to do so in our empirical example presented, we can also imagine an analysis of material arrangements (such as geography/location, infrastructure, etc.) that might have more impact on leadership performances than any leadership method or style does.

We also assert that the teleoaffective elements of human performance - a structure - do not rid agents of agency. Plenty of room exists for both individuality and unexpected outcomes of performance. As Schatzki (2001b) concludes, practice is a process and is therefore becoming. A discourse perspective, as an example of a related form of analysis, should, according to Schatzki, be seen as a product (or a 


\section{O. LINDBERG ET AL.}

snapshot) of this process. In addition, a practice theory analysis of teleoaffective structure does not conflate to rational choices of autonomous individuals. Teleoaffectivity is governing practices and constitutes the history from which humans act and interact. Future actions also shape and reshape this structure.

Interviews and document (policy) analysis are well-suited for the purpose of describing teleoaffective structure. Through interviews, the interviewing researcher has the opportunity to directly ask about what they feel is expected of the leaders. In addition, people have seemed to be quite capable of describing what they do and what they feel are expected of them, as opposed to being asked to account for their beliefs and conceptions of certain phenomena that might be the target of other analyses. Talking about practice is concrete and makes the interview run more smoothly. Policy is also a strong source of mapping expectations, as policy contains explicit formulations of desirable performance. However, policy analysis alone is not sufficient for describing teleoaffective structure of practitioners. On the contrary, policy is, in this example and in many other studies, shown to have a limited impact on practitioners' views. Rather, policy constitutes an important point of reference for interview accounts, in particular, with reference to the expected role as change agents.

There are, however, two important limitations to the analysis we have exemplified in this chapter. First, the analysis of teleoaffective structure through policy and interviews does not primarily describe what leaders actually do or how leaders and followers interact in the construction of leadership. This is why we recommend that practice theory analysis should also incorporate observational data for a rich description of practice. Observation in the form of shadowing (Czarniawska, 2008), where the researcher can also ask questions about motives and goals (why did you do this?) and emotions (how do you feel about this that you do), would be well-suited for this kind of analysis, as it allows for a fine-grained analysis of how practice is accomplished through the 'here-and-now' of situated practicing. Secondly, and contrasting with the first limitation, our chapter does not offer an analysis that specifically targets how leadership practice is connected to what Nicolini (2010, p. 1392) calls the "elsewhere-and-then" of other practices. This type of analysis could take into account how leadership practice is contextualised relative to the historical change of production, division of labour or other cultural and historical conditions. Theoretically, a practice theory framework allows for analysis that acknowledges the local routines of activity while not losing sight of how practice is embedded within, and infused with, wider assemblages of practices (i.e., what Nicolini, 2010, discusses as an analysis that has the capacity to zoom in as well as zoom out). To explicate the connections between local leadership practice and historical, translocal conditions is an important array for further research into the subject. 


\section{Features of a Police Leadership Teleoaffective Structure}

Turning to our empirical example of a practice theory analysis, we are able to draw two main conclusions concerning police leadership practice in times of reorganisation and globalisation. These conclusions are particularly aimed at the readiness of police leaders to constitute change agents (cf., Hooper \& Potter, 2000) in these processes.

First, we conclude that the police leader is in a squeezed position between different domains of expectations. While this conclusion is not new (e.g., Gabel, 2002), we can show how these different and opposing demands result in how these leaders make sense of them in their own leadership performances. The policy texts give the impression that leaders are expected to do everything in every aspect of leadership - from strategist to facilitator. Concurrently, the expectations from above and from below are different from their own ways of leading their units. This mismatch can create a situation in which police leaders experience high pressure pertinent with a squeezed position. The squeeze position of leaders is also highlighted in research into other organisations due to, for instance, economic cutbacks or problems in directing soloists in highly professional organisations (Haikola, 2000; Hailey \& James, 2004). The following is an example of how a police leader reasons about the pitfalls of managing a manifold of expectations:

Today, leaders in my position should be partly operative and partly strategic. We are expected to be quite go-ahead, really. We are expected to have a big range of competencies. (...) [The police] is such a complex organisation and the demands are so various. It's not easy to make it ... it's no assembly line. Sometimes I wonder, the manager position, it's no easy task, both for men and women. And I've noticed that, many are young and have great ambitions, they're very competent, educated, and on top of that have a family to care for. And then to combine this with work ... I mean, a lot of young managers burn out pretty fast because the demands from all directions are quite harsh. (Man 25)

Our second empirically supported conclusion is that these leaders incline towards leading in a way that is more congruent with demands from the lower ranks and immediate daily practice rather than leading in ways that correspond with demands from higher ranks and policy. In short, the Schatzkian 'site' of Swedish police leadership seems to be one that is characterised by everyday issues and similar understandings between leaders and followers. These results align with conclusions from previous studies by, for instance, Andersson and Tengblad (2009) and Harding, Lee, and Ford (2014), who question the passive 'lynchpin' role of middle managers as transmitters of change in the rational top-down implementation of reforms. Rather, a practice theory approach to leadership enables an analysis that recognises that leaders actively engage in re-interpretations and sense-making of strategic plans based on their outlooks on the organisation. 


\section{O. LINDBERG ET AL.}

The case study indicates that such outlooks in large part coincide with traditional 'shop-floor' understandings of whom and what the police should be in contemporary society. It seems as if the interviewed police leaders are more immersed in the daily work of the police and therefore embody police organisational culture more than previously observed. A possible explanation for this is that leaders work within the boundaries of a police culture shared by subordinate workgroups. As indicated by, for instance, Fielding (1994) and Reiner (2000), such a culture contains shared values and norms and a clear us-vs.-them perspective. However, previous research has constructed 'them' as an external outgroup associated with the general public.

Our results indicate that a similar internal us-vs.-them mentality exists within the police between top management and other leader tiers. Thus, it seems that an increasing adoption of new public management strategies and a focus on organisational innovation (cf. Kingshott, 2006; Gordon, 2010) that is promoted from the top management level in the police may result in suspicion and resistance from leaders in lower management positions. Our results indicate that, in light of current changes, these leaders adopt a 'grounded' leadership in which traditional values and employees are safeguarded and prioritised in contrast to the demands posted by top management within the police. As changes presently are implemented from top-down in the Swedish police, our results point towards the conclusion that leaders are reluctant to assume the role of 'change agents'. In conclusion, there is a need for studies on daily leadership practice, as such studies hold great potential to problematise some 'root assumptions' (cf. Alvesson \& Sandberg, 2011) regarding leadership in times of change and turmoil.

\section{REFERENCES}

Alvesson, M., \& Sandberg, G. (2011). Generating research questions through problematization. Academy of Management Review, 36(2), 247-271.

Alvesson, M., \& Sveningsson, S. (2003). Managers doing leadership: The extra-ordinarization of the mundane. Human Relations, 56(12), 1435-1459.

Andersson Arntén, A.-C. (2013). Är Polisen en lärande organisation? En intervjustudie om polisens ledningsstruktur. Stockholm: Rikspolisstyrelsen.

Andersson, T., \& Tengblad, S. (2009). When complexity meets culture: new public management and the Swedish police. Qualitative Research in Accounting \& Management, 6(1/2), 41-56.

Avolio, B. J., Walumbwa, F. O., \& Weber, T. J. (2009). Leadership: Current theories, research, and future directions. Annual Review of Psychology, 60, 421-449.

Bryman, A. (2004). Qualitative research on leadership: A critical but appreciative review. The Leadership Quarterly, 15(6), 729-769.

Butler, J. (1993). Bodies that matter: on the discursive limit of "sex". New York: Routledge.

Czarniawska, B. (2008). Organizing: How to study it and how to write about it. Qualitative Research in Organizations and Management: An International Journal, 3(1), 4-20.

Chia, R. (2004). Strategy-as-practice: Reflections on the research agenda. European Management Review, 1(1), 29-34.

Chia, R., \& Holt, R. (2006). Strategy as practical coping: A Heideggerian perspective. Organization Studies, 27(5), 635-655.

Fielding, N. (1994). Cop canteen culture. In T. Newburn \& E. Stanko (Eds.), Just boys doing business: Men, masculinity and crime (pp. 163-184). London: Routledge, 


\section{POLICE LEADERSHIP IN TIMES OF UNCERTAINTY}

Fleming, J. (2008). Managing the diary: what does a police commissioner do? Public Administration, 86(3), 679-698.

Gabel, S. (2002). Leading from the middle: surviving the squeeze of apparently irreconcilable forces. Leadership \& Organization Development Journal, 23(7), 361-371.

Gill, R. (2002). Change management - Or change leadership? Journal of Change Management, 3(4), 307-318.

Gordon, R. D. (2010). Dispersed leadership: exploring the impact of antecedent forms of power using a communicative framework. Management Communication Quarterly, 24(2), 260-287.

Haake, U., Rantatalo, O., \& Lindberg, O. (forthcoming). Police leaders make poor change agents: Leadership practice in the face of a major organisational reform. Policing \& Society.

Haikola, L. (2000). Att dirigera solister. Om ledning och ledarskap vid Lunds universitet (Directing soloists. Management and leadership at Lund University). Report No. 2000:208. Lund University: Utvärderingsenheten.

Hailey, J., \& James, R. (2004). "Trees Die From the Top": international perspectives on NGO leadership development. Voluntas: International Journal of Voluntary and Nonprofit Organizations, 15(4), 343-353.

Harding, N., Lee, H., \& Ford, J. (2014). Who is "the middle manager"? Human relations, iFirst article.

Hooper, A., \& Potter, J. (2000). Intelligent leadership. Random House: London.

Kingshott, B. F. (2006). The role of management and leadership within the context of police service delivery. Criminal Justice Studies, 19(2), 121-137.

Lauritz, L. E., \& Hansson, J. (2013). Lära är livet - att vara polis i en föränderlig värld (Learning is life - Being a police in a changing world). In N. Eklund \& L. Landström (Eds.), Polisen - verksamhet och arbete (The police - Activity and work) (pp. 66-83). Malmö: Liber.

Lindberg, O. (2012). 'Let me through, I'm a doctor!' Professional socialization in the transition from education to work. Academic Dissertation. Umeå University.

Lindberg, O. (2013). Gatekeepers of a profession? Employability as capital in the recruitment of medical interns. Journal of Education and Work, 26(4), 431-452.

Lindberg, O., \& Rantatalo, O. (2015). Competence in professional practice: A practice theory analysis of police and doctors. Human Relations, 68(4), 561-582.

Nicolini, D. (2010). Zooming in and out: Studying practices by switching theoretical lenses and trailing connections. Organization Studies, 30(12), 1391-1418.

Reiner, R. (2000). The politics of the police ( $3^{\text {rd }}$ ed.). Oxford: Oxford University Press.

Rikspolisstyrelsen (2008). Polisens värdegrund (The police's core values). Stockholm: Rikspolisstyrelsen.

Rikspolisstyrelsen (2011a). Polisens medarbetarpolicy (The police's employee policy). Stockholm: Rikspolisstyrelsen.

Rikspolisstyrelsen (2011b). Polisens ledarkriterier (The police's leader criteria). Stockholm: Rikspolisstyrelsen.

Sandberg, J., \& Tsoukas, H. (2011). Grasping the logic of practice: Theorizing through practical rationality. Academy of Management Review, 36(2), 338-360.

Schatzki, T. (2001a). Introduction: practice theory. In T. Schatzki, K. Knorr Cetina, \& E. Von Savigny (Eds.), The practice turn in contemporary theory (pp. 1-14). New York: Routledge.

Schatzki, T. (2001b). Practice mind-ed orders. In T. Schatzki, K. Knorr Cetina, \& E. Von Savigny (Eds.), The practice turn in contemporary theory (pp. 50-63). New York: Routledge.

Schatzki, T. (2005). Peripheral vision: The sites of organizations. Organization Studies, 26(3), 465-484.

SOU (2012:13). En sammanhållen svensk polis (A unified Swedish police). Stockholm: Regeringskansliet.

Weick, K. E. (1993). The collapse of sensemaking in organizations: the Mann Gulch disaster. Administrative Science Quarterly, 38(4), 628-652. 
O. LINDBERG ET AL.

Ola Lindberg

Department of Education

Umeå University, Sweden

Oscar Rantatalo

Police Education

Umeå University, Sweden

Ulrika Haake

Department of Education

Umeå University, Sweden 